\title{
HISTÓRIAS PROFISSIONAIS: POLÍTICAS DE FORMAÇÃO E PERCURSOS FORMATIVOS DE PROFESSORES
}

\author{
HISTORIAS PROFESIONALES: POLÍTICAS DE FORMACIÓN Y CURSOS DE \\ FORMACIÓN PARA PROFESORES
}

\author{
PROFESSIONAL STORIES: FORMATION POLICIES AND TEACHERS' \\ FORMATIVE PATHWAYS
}

\author{
Marta Rochelly Ribeiro GONDINHO ${ }^{1}$ \\ Luisa Xavier de OLIVEIRA ${ }^{2}$ \\ Maria da Conceição Rodrigues MARTINS ${ }^{3}$
}

RESUMO: O artigo apresenta um estudo investigativo sobre histórias profissionais em interfaces com as políticas de formação docente. O objetivo da pesquisa parte da prerrogativa de analisar histórias de professores e a reverberação das políticas formativas em seus percursos formativos. Para tanto, dialogou-se teoricamente com as contribuições de Nóvoa (1999) e Saviani (2009). As narrativas biográficas construídas a partir de entrevistas orais, foram analisadas destacando as categorias analíticas seguida da aplicação de questionário semiestruturado, caracterizando este estudo de natureza qualitativa em que se toma das narrativas os subsídios para dialogar com elementos bibliográficos. Os achados desta pesquisa sinalizou que as políticas de formação de professores, a legislação vigente e as demandas sociais de um determinado tempo influenciam diretamente nas trajetórias individuais dos professores, entretanto estas políticas não se uniformizam nos percursos formativos, uma vez que cada professor constrói sua história profissional a partir dos modos de recriação da cultura laboral. Destacou-se ainda que na história da formação docente, dada as condições objetivas da razão prática, a cultura profissional incorpora as exigências legais e formativas em muitas circunstâncias de forma acrítica, justificando que o normativo é pra ser incorporado e não questionado, o que evidencia o peso hierárquico das políticas em nossos modos de exercer a docência quando esta consiste em nossa ocupação primária.

PALAVRAS-CHAVE: Histórias profissionais. Políticas de Formação. Percursos formativos.

RESUMEN: El artículo presenta un estudio de investigación sobre historias profesionales en interfaces con las políticas de formación docente. El objetivo de la investigación parte de la prerrogativa de analizar las historias de los docentes y la reverberación de las políticas formativas en sus trayectorias formativas. Para ello, se dialogó teóricamente con los aportes

${ }^{1}$ Universidade Federal do Piauí (UFPI), Teresina - PI - Brasil. Professora Adjunta do Centro de Ciências da Educação (CCE/UFPI). Doutorado em Educação (UFRJ). ORCID: https://orcid.org/0000-0001-9726-2880. Email: martarochelly81@hotmail.com

${ }^{2}$ Universidade Federal do Piauí (UFPI), Teresina - PI - Brasil. Professora Adjunta do Centro de Ciências da Educação (CCE/UFPI). Doutorado em Educação (UFRJ). ORCID: https://orcid.org/0000-0003-0782-4793. Email: luisaxavier77@yahoo.com.br

${ }^{3}$ Universidade Federal do Piauí (UFPI), Picos - PI - Brasil. Professora Adjunta do Campus Senador Helvídio Nunes de Barros (CSHNB/UFPI). Doutorado em Educação (UFU). ORCID: https://orcid.org/0000-0002-74476568. E-mail: flordemariar@outlook.com

RPGE- Revista on line de Política e Gestão Educacional, Araraquara, v. 24, n. 3, p. 1615-1631, set./dez. 2020. e-ISSN:1519-9029 
de Nóvoa (1999) y Saviani (2009). Se analizaron las narrativas biográficas construidas a partir de entrevistas orales, destacando las categorías analiticas seguidas de la aplicación de un cuestionario semiestructurado, caracterizando este estudio cualitativo en el que se toman las narrativas de los subsidios al diálogo con elementos bibliográficos. Los hallazgos de esta investigación señalaron que las políticas de formación docente, la legislación vigente y las demandas sociales de un momento dado inciden directamente en las trayectorias individuales de los docentes, sin embargo estas políticas no se encuentran estandarizadas en las trayectorias formativas, ya que cada docente construye su historia. de las formas de recrear la cultura laboral. También se destacó que en la historia de la formación docente, dadas las condiciones objetivas de la razón práctica, la cultura profesional incorpora requisitos legales y formativos en muchas circunstancias de manera acrítica, justificando que la normativa sea incorporada y no cuestionada, lo que demuestra el peso jerárquico de las políticas en nuestras formas de ejercer la docencia cuando se trata de nuestra ocupación principal.

PALABRAS CLAVE: Historias profesionales. Politicas de formación. Cursos de formación.

ABSRACT: The article presents an investigative study on professional histories in interfaces with teaching training policies. The objective of the research is based on the prerogative of analyzing teachers' histories and the reverberation of formative policies in their formative paths. For this purpose, a theoretical dialogue was held with the contributions of Novoa (1999) and Saviani (2009). The biographical narratives constructed from oral interviews were analyzed highlighting the analytical categories followed by the application of a semistructured questionnaire, characterizing this study of a qualitative nature in which one takes from the narratives the subsidies for dialogue with bibliographical elements. The findings of this research indicated that teacher training policies, current legislation and the social demands of a given time have a direct influence on the individual trajectories of teachers. However, these policies are not uniform in the training paths, since each teacher builds his or her professional history based on the ways of recreating the work culture. It has also been highlighted that in the history of teacher education, given the objective conditions of practical reason, professional culture incorporates legal and formative requirements in many circumstances in an uncritical way, justifying that the normative is to be incorporated and not questioned, which highlights the hierarchical weight of policies in our modes of teaching when it consists of our primary occupation.

KEYWORDS: Professional stories. Formation Policies. Formative pathways.

\section{Introdução}

A história social do magistério é uma arena feita de um conjunto de histórias que se interpenetram: História da construção do campo intelectual da educação e da profissão, história das lutas e estratégias dos professores em relação ao Estado, história da construção da escola e do conhecimento que nela circula (LELIS, 2001, p. 41).

Histórias que se misturam e se envolvem, se encontram e desencontram formam essa rede complexa que denominamos história da profissão docente. Histórias que se interpenetram como sinalizou Isabel Lelis. É deste campo de lutas diárias, de estratégias 
cotidianas travadas em relação ao Estado, de histórias do chão da escola e das inúmeras formas de produzir com o conhecimento que tomamos assento quando optamos pela docência enquanto nossa profissão.

Perguntas e muitas indagações fazem parte deste conjunto de histórias. Ao longo dessa pesquisa pensou-se ter algumas das respostas que nos levaram a pesquisar. Tal prerrogativa nos inquietava, afinal nós professores estamos numa trama que se democratizou de tal forma que supomos conhecer um pouco sobre tudo quando o assunto é nosso trabalho e nossa profissão. Ledo engano. Com a pesquisa, algo nos chama atenção de imediato: como somos tão diferentes em nossos percursos? Como enquanto categoria profisssional, pensamos tão diferente? Como nos encontramos em alguns aspectos mesmo sendo de gerações tão distintas?

Este artigo amparou-se nas seguintes questões: como é constituído o percurso formativo de professores em uma escola confessional católica em Teresina-Piauí? Qual o lugar das políticas educativas do Estado na constituição da identidade profissional de professores em um contexto escolar confessional católico? Estas questões nortearam nosso investimento reflexivo e analítico. Nosso objetivo foi compreender, através das trajetórias profissionais, os percursos formativos de professores na escola confessional católica Irmã Maria Catarina Levrini em Teresina-Piauí, identificando o papel das políticas educativas do Estado, bem como da política institucional nas trajetórias destes professores.

\section{Políticas de formação e percursos formativos de professores}

Nas sociedades contemporâneas, uma das chaves principais para a compreensão de suas mudanças é ação dos professores desempenhada no campo profissional. Nossa análise sobre a identidade profissional foi empreendida a partir do recorte temporal da década de 1950 no Brasil, entretanto, nos reportaremos a uma breve compreensão do final do século XVIII e início do século XIX para pensar as relações demarcadas pelo Estado sobre a funcionarização dos professores.

No contexto brasileiro, as especificidades da formação de professores situam-se historicamente na constituição singular da rede escolar (sua oferta/expansão) que adquirindo um desenho específico no final do século XIX criam as Escolas Normais destinadas à formação dos professores para as escolas de primeiras letras.

Para Saviani, o fato de nos reportarmos ao século XIX para demarcarmos as discussões alusivas à formação de professores dar-se-á por ser neste recorte temporal que esse 
discurso aparece de forma explícito, mas não significa dizer que não havia discussões sobre a preparação dos professores anteriormente à primeira metade do século XIX. Para o autor,

Durante todo o período colonial, desde os colégios jesuítas, passando pelas aulas régias implantadas pelas reformas pombalinas até os cursos superiores criados a partir da vinda de D. João VI em 1808, não se manifesta preocupação explícita com a questão da formação de professores. É na Lei das Escolas de Primeiras Letras, promulgada em 15 de outubro de 1827, que essa preocupação apareceu pela primeira vez. Ao determinar que o ensino, nessas escolas, deveria ser desenvolvido pelo método mútuo, a referida lei estipula no artigo $4^{\circ}$ que os professores deverão ser treinados nesse método, às próprias custas, nas capitais das respectivas províncias. Portanto, está colocada aí a exigência de preparo didático, embora não se faça referência propriamente à questão pedagógica (SAVIANI, 2009, p. 144).

Ao traçar exigências formativas/habilidades, se demarca nesse corpo de professores exigências que atendem a uma conjuntura da época, conformam uma lógica de poder e acionam a constituição do seu habitus científico. Os percursos formativos dos professores têm uma relação ideológica entre o projeto de sociedade que se pretende formar e os ditames do Estado sob o formato de conformação de um corpo coletivo de trabalhadores que conquistou reconhecimento social.

Quando a instrução primária passa a ser de responsabilidade das províncias, estas criam as Escolas Normais que terão como foco a preparação formativa dos professores. De antemão, a proposta destes espaços formativos era formar habilidades específicas para o exercício do magistério, entretanto, o que se viu foi uma transposição do currículo das escolas de primeiras letras para o curso de formação de professores. Destarte, a reforma das Escolas Normais era uma condição de melhor formação de professores e estava alicerçada em dois pontos cruciais: melhoramento do conteúdo curricular e ênfase nos aspectos práticos o que implicaria uma melhor formação didático-pedagógica.

Outro marco significativo na perspectiva institucional da formação de professores é a criação dos Institutos de Educação sob a égide do ideário escolanovistas, preconizados por Anísio Teixeira e Fernando de Azevedo. As Escolas Normais são transformadas em escolas de professores e os Institutos de Educação são preparados para incorporar as exigências da pedagogia. Os Institutos foram elevados ao nível universitário tornando-se bases de estudos superiores. Saviani destaca que

Os Institutos de Educação do Distrito Federal e de São Paulo foram elevados ao nível universitário, tornando-se a base dos estudos superiores de educação: o paulista foi incorporado à Universidade de São Paulo, fundada em 1934, e o carioca foi incorporado à Universidade do Distrito Federal, 
criada em 1935. E foi sobre essa base que se organizaram os cursos de formação de professores para as escolas secundárias, generalizados para todo o país a partir do decreto-lei n. 1.190, de 4 de abril de 1939, que deu organização definitiva à Faculdade Nacional de Filosofia da Universidade do Brasil. Sendo esta instituição considerada referência para as demais escolas de nível superior, o paradigma resultante do decreto-lei $\mathrm{n}^{\circ} 1.190$ se estendeu para todo o país, compondo o modelo que ficou conhecido como "esquema $3+1$ " adotado na organização dos cursos de licenciatura e de Pedagogia. Os primeiros formavam os professores para ministrar as várias disciplinas que compunham os currículos das escolas secundárias; os segundos formavam os professores para exercer a docência nas Escolas Normais. Em ambos os casos vigorava o mesmo esquema: três anos para o estudo das disciplinas específicas, vale dizer, os conteúdos cognitivos ou "os cursos de matérias", na expressão de Anísio Teixeira, e um ano para a formação didática (SAVIANI, 2009, p. 146).

Ao institucionalizar os espaços de formação de professores, caminhou-se a passos largos para incorporar e consolidar as exigências de instrução da categoria. A profissão docente já não poderá ser exercida por amadores ou detentores de um conhecimento sofisticado, ela começa então a se enquadrar em uma cultura profissional em que a profissão é entendida como um ofício que tem história e uma rede de conhecimentos consolidados.

Para Saviani (2009, p. 36), a periodização da história da formação de professores no Brasil pode ser sintetizado em

1. Ensaios intermitentes de formação de professores (1827-1890). Esse período se inicia com o dispositivo da Lei das Escolas de Primeiras Letras, que obrigava os professores a se instruir no método do ensino mútuo, às próprias expensas; estende-se até 1890, quando prevalece o modelo das Escolas Normais. 2. Estabelecimento e expansão do padrão das Escolas Normais (1890-1932), cujo marco inicial é a reforma paulista da Escola Normal tendo como anexo a escola-modelo. 3. Organização dos Institutos de Educação (1932- 1939), cujos marcos são as reformas de Anísio Teixeira no Distrito Federal, em 1932, e de Fernando de Azevedo em São Paulo, em 1933. 4. Organização e implantação dos Cursos de Pedagogia e de Licenciatura e consolidação do modelo das Escolas Normais (1939-1971). 5. Substituição da Escola Normal pela Habilitação Específica de Magistério (1971-1996). 6. Advento dos Institutos Superiores de Educação, Escolas Normais Superiores e o novo perfil do Curso de Pedagogia (1996-2006).

As trajetórias de formação profissional que serão analisadas neste artigo estão circunscritas entre os anos de 1957 e 2003, o que se aproxima do recorte de análise proposta por Saviani no tocante à organização e implantação dos Cursos de Pedagogia e de Licenciatura e à consolidação do modelo das Escolas Normais (1939-1971), a substituição da Escola Normal pela Habilitação Específica de Magistério (1971-1996) e o Advento dos Institutos Superiores de Educação, Escolas Normais Superiores e o novo perfil do Curso de Pedagogia (1996-2006). 
Quadro 7 - Síntese das exigências normativas/ legais relativas à formação dos profissionais da educação

\begin{tabular}{|c|c|c|}
\hline LEI $N^{\circ} 4024 / 61$ & LEI N5692/71 & LEI No 9394/96 \\
\hline $\begin{array}{c}\text { CAPÍTULO V } \\
\text { Da Formação do Magistério } \\
\text { para o ensino primário e médio }\end{array}$ & $\begin{array}{c}\text { CAPÍTULO V } \\
\text { Dos professores e especialistas }\end{array}$ & $\begin{array}{c}\text { TÍTULO VI } \\
\text { Dos profissionais da Educação }\end{array}$ \\
\hline $\begin{array}{l}\text { Art.53 A formação de docentes } \\
\text { para o ensino primário far-se-á: a) } \\
\text { em escola normal de grau } \\
\text { ginasial, no mínimo de quatro } \\
\text { séries anuais, onde, além das } \\
\text { disciplinas obrigatórias do curso } \\
\text { secundário ginasial, será } \\
\text { ministrada preparação } \\
\text { pedagógica; b) em normal de } \\
\text { grau colegial, de três séries } \\
\text { anuais, no mínimo, em } \\
\text { prosseguimento ao grau ginasial. }\end{array}$ & $\begin{array}{l}\text { Art.30 Exigir-se-á como formação } \\
\text { mínima para o exercício do } \\
\text { magistério: a) no ensino de } 1^{\circ} \text { grau, } \\
\text { da } 1^{\mathrm{a}} \text { à } 4^{\mathrm{a}} \text { séries, habilitação } \\
\text { específica de } 2^{\circ} \text { grau; b) no ensino } \\
\text { de } 1^{\circ} \text {, da } 1^{\mathrm{a}} \text { a } 8^{\mathrm{a}} \text { séries, habilitação } \\
\text { específica de grau superior, ao nível } \\
\text { de graduação, representada por } \\
\text { licenciatura de } 1^{\circ} \text { grau, obtida em } \\
\text { curso de curta duração; c) em todo } \\
\text { o ensino de } 1^{\circ} \text { e } 2^{\circ} \text { graus, } \\
\text { habilitação específica obtida em } \\
\text { curso superior de graduação } \\
\text { correspondente a licenciatura plena. }\end{array}$ & $\begin{array}{l}\text { Art.62. A formação de docentes para } \\
\text { atuar na educação básica far-se-á em } \\
\text { nível superior, em curso de } \\
\text { licenciatura de graduação, em } \\
\text { universidades e institutos superiores } \\
\text { de educação, admitida, como } \\
\text { formação mínima para o exercício do } \\
\text { magistério na educação infantil e nas } \\
\text { quatro primeiras séries do ensino } \\
\text { fundamental, a oferecida em nível } \\
\text { médio na modalidade normal. }\end{array}$ \\
\hline
\end{tabular}

Fonte: Davies (2004)

De acordo com o quadro acima é possível identificar o Estado assumindo o controle dos processos formativos dos professores. Os professores, por sua vez, para não se encontrarem em defasagem formativa e se tornarem leigos diante de novas expectativas formativas, necessitam se enquadrar nesses dispositivos de controle. O Estado constrói políticas de incentivo formativo e, ao mesmo tempo, constrói um mercado acirrado de disputas no setor educativo. A exemplo,

Não era nada fácil entrar no seletivo do Instituto de Educação Antonino Freire. Tinha um livro chamado de exame de admissão que você precisava adquirir para se preparar. Aqueles que não conseguiam passar no seletivo concorridíssimo tinha que pagar cursos pedagógicos privados, o que não cabia na realidade de muitas jovens do Piaui afora, que assim como eu tiveram que trabalhar inicialmente no comércio para juntar o dinheiro de pagar o pedagógico. Se você não fizesse isso não tinha habilitação para as séries primárias, o que era exigido pelas escolas no início dos anos de 1980 (Trecho Magister C).

Cada um por iniciativa própria luta pela sua formação, queríamos ter nossa profissão, ser professora! Tinham muitos alunos oriundos das classes mais privilegiadas de Teresina e do Piaui como um todo na Escola Normal, mas também tinham aqueles que, assim como eu, fizeram um alto investimento de deslocamento, de se manter na cidade, de investir em vestimenta e material de estudo. Ser professor na década de 1970 era um desejo tanto das classes mais favorecidas, especialmente das mulheres, quanto das classes menos favorecidas, mas uma coisa se tinha em mente: para ser professor a partir de então se faz necessário uma formação específica (Trecho Magister B).

RPGE- Revista on line de Política e Gestão Educacional, Araraquara, v. 24, n. 3, p. 1615-1631, set./dez. 2020. e-ISSN:1519-9029 
Ainda rememorando a história da formação de professores no Brasil para compreender a história da profissão docente no país e a formação de professores é importante destacar um duplo contexto caracterizado, por um lado, pelo processo de formação dos Estados modernos e, por outro, pelo processo de institucionalização das ciências da educação. Ambos representam uma possibilidade teórico-analítica para desvelar os desdobramentos acerca da constituição profissional do professor.

Para Nóvoa (1999), tanto em Portugal como no Brasil, a funcionarização do professorado de forma tutelada pelo Estado constitui um dos marcos tanto de controle dos processos educativos quanto da profissão docente. Esta última a ser pensada criticamente não só a partir do recrutamento do Estado, mas desde a conformação do status profissional aos modos inventivos subversivos de operar a docência.

No universo docente corpos de normatividade, saberes e práticas foram dinamizados ao longo do tempo em conformação a um ofício e não como a uma profíssão, assim podemos entender a constituição profissional do professor pela funcionarização estatal, uma vez que

durante longos anos imputou-se a gênese da profissão docente à ação dos sistemas estatais de ensino; hoje em dia, sabemos que no início do século XVIII havia já uma diversidade de grupos que encaravam o ensino como ocupação principal, exercendo-a por vezes a tempo inteiro. A intervenção do Estado vai provocar uma homogeneização, bem como uma unificação e uma hierarquização à escala nacional, de todos estes grupos: é o enquadramento estatal que institui os professores como corpo profissional, e não uma concepção corporativa do ofício (NÓVOA, 1999, p. 17).

Ao funcionarizar os professores, não podemos entender que é apenas a construção de mais uma profissão, dada à intencionalidade política que esta apresenta em seu bojo devido aos projetos e as finalidades sociais de que são portadores, esta se configura como uma profissão peculiar, estratégica. A sua produção nutre uma expectativa social de transformação, tendo em vista as possibilidades de inclusão e ascensão social (XAVIER, 2013).

A produção da profissão sustenta expectativas de mudanças desde o início do século XX. A finalidade desta profissão traz em sua gênese uma perspectiva de transformação da sociedade, por outro lado em se tratando da profissionalização docente especificamente a partir dos anos de 1960 no Brasil, esta escolha profissional também é o reflexo de mudança social para os que a escolhem como ocupação principal como sinalizou a autora ao identificar que

Durante o regime militar (1964-1985) o magistério deixou de ser exclusivamente às classes médias e urbanas e frações das elites, passando a constituir-se também das camadas populares. Ocorreu, assim, um processo 
de mobilidade tanto ascendente quanto descendente, pois os que tinham origem nos de cima se proletarizaram enquanto os de origem populares ascenderam a uma profissão de classe média. A nova categoria, formada por essas duas frações, foi submetida a condições de vida e de trabalho determinadas pelo arrocho salarial (BITTAR, 2006, p. 1159).

No estado do Piauí, esta profissão constitui uma alternativa de ascensão para as classes mais populares e, para a classe média, significou a conformação de uma nova condição social/vida delimitada pelo arrocho salarial. No caso das cinco professoras depoentes desta pesquisa, observa-se que todas se encontravam no grupo que ascenderam socialmente pela escolha da carreira.

Em vista do exposto, nosso olhar volta-se para o percurso formativo destas professoras a partir de um viés institucional. Como estas professoras da Escola Irmã Catarina Levrini que ascenderam socialmente pela carreira docente se preparavam para a profissão?

No meu início de carreira, a Escola Normal era o lugar de preparação dos professores para o exercício do magistério em meados do final da década de 1970 e início dos anos 1980, depois mudaram as leis e tivemos que lutar pelo ingresso nas universidades (Trecho Magister A).

Ingressei na Escola Normal objetivando me tornar professora para ingressar no mercado de trabalho. No final dos anos de 1990 iniciei o curso de História na Universidade Estadual do Piaui através do periodo especial (Trecho Magister B).

Quem desejava ser professor sabia que deveria cursar a Escola Normal. Inicialmente fiz a Escola Normal nos anos de 1980 e no final dos anos de 1990 ingressei no ensino superior no curso de Pedagogia (Trecho Magister D).

A preparação formativa das professoras/magister A, B e D sinaliza para identificação da Escola Normal como lugar formativo privilegiado dos professores da cidade de Teresina, entre os anos de 1970 e 1980.

Como não consegui ingressar na Escola Normal fiz o pedagógico privado nos anos de 1980. Nos anos 2000 senti a necessidade de um curso superior, fiz então uma faculdade privada e me formei em filosofia (Trecho Magister C)

As classes populares nem sempre tiveram sucesso nas buscas por espaços formativos, a exemplo a fala supracitada da magister C. Cabia então outras tentativas como a formação em espaços privados de ensino. Essa evidência típica de uma sociedade de classes com oportunidades desiguais de acesso ao ensino será percebida até os dias atuais, uma parte 
significativa das classes populares que almejam ascensão social via estudos recorrem à inciativa privada para realizarem suas experiências formativas.

Ainda sobre os caminhos percorridos pelas professoras em sua busca formativa, transcorrida a década de 1980 e de duas leis de diretrizes e bases (Lei nº4024/61 e nº 5692/71) com definições sobre as exigências normativas de formação de professores, é na década de 1990 que se combinará a formação de professores com o ingresso em cursos superiores oferecidos pelas universidades (formação inicial), mais especificamente com a LDBEN n ${ }^{\circ}$ 9394/96.

Decidi ser professora já nos anos de 1990. Neste período já vislumbrava o acesso ao curso universitário. Cursar pedagogia na Universidade Federal do Piaui era a minha primeira decisão profissional, professora em formação para o exercício da docência nas séries iniciais do ensino fundamental (Trecho Magister E).

Nas falas das professoras sobre seus trajetos formativos, identificamos que o projeto formativo da docência em um contexto social, político e econômico tanto apresentam os indícios normativos do Estado como também apresentam enredos muito particulares de operações empreitadas pelos sujeitos que aderem à docência como profissão.

Os percursos formativos exigidos institucionalmente pela escola em estudo nesta pesquisa não eram diferentes aos exigidos pelo contexto normativo em vigor. As normas de ingresso sinalizavam que a escola estava sintonizada como os contextos legais preconizados pela lei de diretrizes e bases da educação nacional, entretanto pelas narrativas docentes, evidenciou-se que as exigências normativas não eram as condições únicas para a análise do perfil docente:

Quando fui contratada para trabalhar no Catarina Levrini já era formada pela Escola Normal. As irmãs exigiam formação mas, juntamente com o diploma, elas faziam outras exigências como ser mulher, ser cristã e morar nas proximidades da escola (Trecho Magister A).

Quando fui contratada pela escola eu já era funcionária do Estado. As irmãs pediram indicação na gerência de ensino, elas queriam boas professoras, até então eram as irmãs as professoras da escola, mas com as mudanças de leis e também pelo fato das irmãs já se encontrarem bastante idosas foi firmado uma parceria com o governo do Estado que concedeu os professores e a merenda escolar para que a escola não deixasse de funcionar. As irmãs exigiam dos professores contratados diploma e realizam entrevistas para conversar sobre sua vida pessoal, suas crenças e, é logico, suas habilidades. As irmãs eram bastante exigentes, queriam montar um quadro de professores com excelência, assim selecionavam tanto pela formação, quanto pelas qualidades pessoais do professor (Trecho Magister B). 
Em ambas as narrativas das professoras se percebem que os mecanismos de recrutamento estavam atrelados tanto aos dispositivos normativos do Estado quando elas se referem a ser diplomadas de acordo com a lei, quanto às qualidades de ordem pessoais. A escola como instituição contratante do professor faz exigências para além dos aspectos formativos como: ter habilidades para compor uma equipe de excelência no tocante ao ensino, ser mulher e morar nas proximidades da escola. Tais exigências sinalizam que as questões normativas para a contratação de professores serão condições de ingresso na carreira docente, mas as exigências subjetivas exercerão pesos de também enorme valia como gênero, moradia e habilidades/saberes pedagógicos e alguns atributos pessoais e religiosos.

A forma de ingresso institucional era no primeiro momento da história da escola associada ao Estado que concedia pessoas do seu quadro de trabalho para a escola seguido de um recrutamento via entrevista realizada pelas irmãs.

O ritual de ingresso era uma triagem exigente de qualidades pessoais e profissionais entendidas como pré-requisitos para a constituição do quadro docente que comporia por muitos anos a equipe de professores da escola irmã Maria Catarina Levrini.

Ao longo da seleção inicial e dos primeiros anos de experiência na escola as professoras eram submetidas às formações em serviço cedidas pela própria escola que tinha como objetivo elevar suas potencialidades em relação ao trabalho que executavam, bem como preparar o espírito para a realização da nobre missão de educar.

"Os professores, por sua vez, são agentes culturais e agentes políticos”, segundo Nóvoa (1999), sendo os professores “os protagonistas no terreno da grande operação histórica da escolarização, assumindo a tarefa de promover o valor educação; ao fazê-lo criam condições para a valorização de suas funções". Segundo o autor, é acentuada nesta perspectiva uma percepção sobre a profissionalização que circunstancialmente provoca uma discussão acerca da identidade docente dada as exigências sociais.

Para as professoras submetidas a este tipo de recrutamento, especulava-se a conformação de um modelo formativo do professor para atuar em escolas confessionais católicas ligadas à filantropia. No imaginário docente, construía-se um perfil profissional institucional que enfatizava as habilidades docentes, as questões de gênero, a opção religiosa e os comportamentos sociais em favor dos que mais necessitavam.

Para ser professora de uma escola como era o IMCL que ia lidar com a supervisão das irmãs e suas crenças socializadas a cada momento, se fazia necessário ser cristã, ser mulher de preferência casada, morar perto devido à exclusividade e ao tempo integral e, de 
preferência, que os filhos estudassem na escola com o objetivo de zelar sempre pela qualidade (Trecho Magister A).

Martin Lawn ${ }^{4}$ (2001) aponta que as identidades são construídas e manipuladas através dos discursos, uma vez que ela é gerada ao longo do tempo e moldada em ajustes ao contexto econômico e social. No caso específico dos professores em que o trabalho docente é socialmente construído e que a identidade é um aspecto importante para a tecnologia do trabalho, esta é ajustada ao projeto educativo do Estado, traduzindo-se em um método sofisticado de controle e em uma forma eficaz de gerir mudanças. Para o autor,

a identidade é produzida através de um discurso que, simultaneamente, explica e constrói o sistema. A Identidade do professor simboliza o sistema e a nação que o criou. Reflete a comunidade imaginada da nação, em momentos em que esta é crucial para o estabelecimento ou reformulação dos seus objetivos econômicos ou sociais, tal como se encontram definidos pelo Estado (LAWN, 2001, p. 118).

Acrescento a Lawn (2001) que a identidade é ajustada também pelo projeto educativo institucional. As escolas confessionais ocupavam em meados dos anos de 1970, no Piauí, um status social arrojado que tinha um lugar reconhecido no projeto de sociedade. As professoras, em sua maioria, queriam traçar carreira nos seus interiores por reconhecer a importância social destes espaços e também pelo fato de que, para a maioria das professoras, estas escolas eram também o lugar por excelência da experiência escolar de seus filhos.

'A gestão da identidade dos professores é um ponto crucial para a compreensão dos sistemas educativos' (LAWN, 2001, p. 118). Identificar os sentidos atribuídos à docência ao longo do tempo nos permite entender um projeto de nação, de civilidade e de expectativas em relação aos desejos enfatizados pelo inacabado projeto de modernidade.

Corroborando com Lawn (2001), destacamos trechos de falas das professoras pra legitimar a ideia de que a identidade reflete o sistema e a nação que o criou, são eles:

${ }^{4}$ Nota biográfica/trajetória profissional: Martin Lawn é professor em Brighton Faculdade de Educação. Tornou-se pesquisador no Instituto de Estudos Avançados em Humanidades, pesquisador no centro de Sociologia Educacional, ambas na universidade de Edimburgo. Foi Secretário Acadêmico do BERA e Secretário-Geral, Associação Educacional Europeu de investigação. Foi professor visitante na Faculdade de Formação de Professores, e anterior da Faculdade de Ciências Sociais da Universidade de Umea, na Suécia, e da Universidade de Edinburgh e, atualmente, na Universidade de Turku, na Finlândia. Ele é um especialista associado, Instituto Europeu de Educação e Política Social, Paris e foi Professor Visitante na Facultad Latinoamericana de Ciências Sociales (FLACSO), em Buenos Aires. É o editor do 'European Educational Research Journal ", o jornal acadêmico da União Europeia Educational Research Association e membro de conselhos editoriais, Revue Française de Pédagogie ea Sociologia da Educação italiano Journal e membro da Academia de Ciências Sociais. 
Nós professores temos uma missão que é transformar as pessoas, formar cidadãos. Nossa remuneração não é muita, mas é suficiente para viver com dignidade, professor não é profissão que se escolhe pensando em ficar rico, em ganhar dinheiro, se escolhe ser professor primeiramente por missão (Trecho Magister B).

Nós professores, com o passar do tempo, não temos tempo mais para nada, por isso que achamos envolvimento sindical ação de quem não tem o que fazer, embora saiba de sua importância. Estamos sempre tão ocupados, não temos tempo para cuidar de nossos estudos para além da escola ou mesmo de nossas atividades culturais. Nem lembro a última vez que fiquei sem fazer absolutamente nada um dia inteiro, é prova, é planejamento, é aula, é pósgraduação, é formação continuada, enfim, extremamente sobrecarregadas (Trecho Magister E).

Nós professores somos cobrados em tudo, por tudo e por todos. Certo dia eu estava pensando se nossa profissão é tão importante para a transformação do país porque a greve dos motoristas de ônibus tem mais impacto do que a greve dos professores. É lamentável ver o que as autoridades públicas do nosso país fazem com a categoria dos professores. Aqui em Teresina, a polícia recebe ordem é para bater nos professores. Na câmara dos vereadores, professores são desrespeitados toda vez. Fico pensando que no discurso é uma coisa e na realidade é outra, também sei que é estratégico a falta de respeito com a categoria, o objetivo é enfraquecer o grupo de professores. E o pior é que o Estado consegue (Trecho Magister D).

Nossa categoria é desunida mesmo, ninguém entra em consenso, uns grevam, outros não, uns estão satisfeitos com o salário e outros não, uns denunciam as condições precárias de trabalho, outros não. A prefeitura municipal de Teresina, nos últimos anos, tem feito atrocidades como padronizar os planos de aulas dos professores, a mesma sequência didática para todo mundo, eu já ouvi professores dizendo que isso é certo demais, outros se recusando a tal exigência. Fico imaginando que, para os sistemas de ensino, professor bom é aquele que não discute e que concorda com tudo que vem de cima para baixo (Trecho Magister A).

Em escola privada você dança conforme a música, não dá pra ser do contra sempre, é logico que temos direito a ter nossas opiniões, mas trabalhar na iniciativa privada significa calar mais que falar, eu aprendi isso com o tempo (Trecho Magister C).

Identificamos nos trechos das falas das cinco professoras que o discurso produzido coincide com os dilemas da profissão traçados por Lawn no tocante à fabricação da identidade docente. A identidade dos professores tem traços marcantes de manobras do Estado percebido pelos seus métodos sofisticados de controle como, por exemplo, o fato dos professores não fazerem parte da agenda de prioridade das políticas de Estado e de governo, bem como de pautas específicas de melhoramento da educação, entretanto, nos discursos políticos aferidos, acredita-se que compete a esta categoria as mudanças mais significativas da sociedade. 
Questões assinaladas nas falas dos professores acima como: precárias condições de trabalho, imposições institucionais da rede privada de ensino, desvalorização do status, defasagem salarial, imposições de ações pedagógicas autoritárias, sinalizam entre tantas outras a percepção de projeto educativo que baliza determinadas políticas de controle educacional.

No modelo de análise da profissão docente esboçada por Nóvoa (1999), o processo histórico de profissionalização do professorado circula entorno de quatro etapas, duas dimensões e um eixo estruturante que podem ser tanto estudados na perspectiva diacrônica, quanto sincrônica. As quatro etapas são: ocupação principal, licença do Estado, formação e associativismo seguida de duas dimensões (conhecimento/técnica e normas/valores) e um eixo central denominado de estatuto social e econômico. Este esboço tem uma dimensão histórica que o circunscreve no tempo e possibilita perceber mudanças e permanências ao longo dos tempos.

Os elementos do modelo analítico citado são identificáveis socialmente porque o trabalho profissional do professor se democratizou de tal forma que os agentes que estão imersos neste processo o identificam de forma nítida. A identificação utiliza categorias socialmente disponíveis e mais ou menos legítimas em níveis diferentes designações oficiais de Estado, denominações éticas, regionais, profissionais, até mesmo idiossincrasias diversas (DUBAR, 2005).

Cabe ressaltar que estudos de muitas naturezas sobre a constituição professoral foram, desde o século XVIII, evidenciados em notas de jornais, panfletos de circulação, registros pessoais de intelectuais e de pessoas comuns que viveram os feitios professorais ou que redigiram suas impressões sobre estes em memoriais, crônicas ou diários pessoais, porém estes evidenciavam a existência de um ofício. É no limiar do século XX que identificaremos iniciativas de estudos sobre a profissão docente amparados em análises sobre o percurso/itinerário e dilemas da profissão.

O processo histórico da profissionalização, por estar atrelado à formação dos Estados modernos e de seus sistemas de escolares, se aproxima de experiências empreendidas em outros países conferindo a esta ideia um caráter transnacional. Isso justifica uma aproximação analítica de nossas realidades com a de outros países a citar o exemplo de Portugal.

Os anos da década de 1980 foram marcados pelas constantes iniciativas de pesquisa em torno da formação de professores; nos permitiu identificar nos estudos das identidades, especialmente no campo educacional, uma discussão sobre a preparação dos professores para o ensino, as formas de seleção para o ofício, as condições de trabalho, as questões salariais, a 
carreira docente, os movimentos de profissionalização a citar Catani (1998), Bittar (2006) e Xavier (2003).

O entendimento do termo profissionalização como o processo de formação do sujeito em uma profissão foi tomado como elemento de problematização durante a análise das trajetórias de professores, uma vez que compreendemos que

\begin{abstract}
ao escolher ou entrar numa profissão uma pessoa define um modo de vida. Começa a pertencer a um grupo que, conforme o seu grau de identificação, lhe traz benefícios ao atender a uma das necessidades humanas básicas, a de pertencimento. A vivência cotidiana numa profissão e instituição geralmente interfere de maneira vigorosa no desenvolvimento da própria identidade ou "identidade do eu". Nesse sentido, é possível entender a palavra profissionalidade como a fusão dos termos profissão e personalidade. $\mathrm{O}$ termo profissionalização indica o processo de formação de um sujeito numa profissão, que se inicia com a formação inicial e atravessa todos os momentos de formação continuada (PENIN, 2009, p. 3).
\end{abstract}

Assim, adentramos as reminiscências das professoras sobre seus processos formativos, entendendo que a profissão desenha um modo de vida e que o modo de vida desenha a profissão. Desse modo, entendemos que o Estado ao funcionarizar os professores, lançou um projeto arrojado de homogeneização, mas os feitos que singularizam cada professor provoca um novo arranjo. Temos, assim, professores construindo a docência entre estratégias e táticas.

\title{
Considerações
}

Este estudo analítico teve como objetivo compreender, através das trajetórias profissionais, os percursos formativos de professores na escola confessional católica Irmã Maria Catarina Levrini em Teresina-Piauí, identificando o papel das políticas educativas do Estado, bem como da política institucional nas trajetórias destes professores, ao final deste, entendemos que os percursos formativos dos professores estão assentados em causas objetivas que carregam as marcas de um cenário histórico. A profissão é data no tempo e tem as singularidades dos contextos no qual a mesma está inserida. As políticas de estado conformam comportamentos coletivos profissionais ao funcionarizar os professores e os enquadrá-los em um regime normativo vertical que institui regras, valores e padrões regimentados por um currículo, por políticas públicas educacionais, por avaliações institucionais de larga escala e por engendramento de imaginário alusivos às condutas docentes.

Do ponto de vista dos percursos formativos situados a partir da experiência institucional, ressaltamos que as escolas confessionais católicas constroem baseado nos 
princípios ideológicos da igreja um corpo de saberes institucionalizados que balizam seus feitios diários na dinâmica de manutenção da fé cristã e na conformação de um ideal de qualidade de oferta de serviços educacionais a dois segmentos distintos da sociedade: elite e camadas populares. Ambos, embora amparados sob a fé cristã com mecanismos sociais distintivos tão transparentes.

Assim, as políticas institucionais e de estado podem ser entendidos como dois dispositivos de poder que inculcam formas contextuais de entendimentos valorativos sociais, culturais e políticos conforme uma lógica declarada ou não. Por outro lado, os professores em suas singularidades acionam diariamente por seus feitos táticas inventivas que dão corpo às mudanças, às transformações cotidianas e a um conjunto de repertórios autênticos que caracterizam o terreno profissional da docência como algo tão dinâmico em sua natureza.

Trajetos são evidências dessa dinamicidade profissional que faz da docência uma profissão plural!

\section{REFERÊNCIAS}

BOURDIEU, P.; PASSERON, J. A reprodução: elementos para uma teoria do sistema de ensino. Rio de Janeiro: Francisco Alves, 1982.

BRASIL. Decreto n. 64.969 de 11 de agosto de 1969. Aprova o Estatuto da Fundação Universidade Federal do Piauí. Diário Oficial da União: Seção 1, Brasília, DF, p. 7057, 20 ago. 1969.

BRASIL. Lei n. 4.024, de 20 de dezembro de 1961. Fixa as Diretrizes e Bases da Educação Nacional. Diário Oficial União: Seção 1, Brasília, DF, p. 11429, 27 dez. 1961.

BRASIL. Lei n. 9.394, de 20 de dezembro de 1996. Estabelece as diretrizes e bases da Educação Nacional. Diário Oficial da União: Seção 1, Brasília, DF: MEC, p. 27833, 23 dez. 1996. PL 1258/1988.

CARIA, T. H. A cultura profissional do professor de ensino básico em Portugal: uma linha de investigação a desenvolver. Sísifo: Revista de Ciências da Educação, Lisboa (Portugal), n. 3, p. 125-138, 2007.

CATANI, D. B. Estudos de história da profissão docente. In: LOPES, E. M. T. et al. $\mathbf{5 0 0}$ anos de educação no Brasil. Belo Horizonte: Autêntica, 2003.

CERTEAU, M. A escrita da história. Rio de Janeiro: Forense universitária, 1982.

CHARTIER, R. Por uma Sociologia histórica das práticas culturais. In: A História Cultural entre práticas e representações. Lisboa: DIFEL, 1990.

DAVIES, N. Legislação educacional federal básica. São Paulo: Cortez, 2004. 
DUBAR, C. A Socialização: construção das identidades sociais e profissionais. Trad. Andréa Stahel M. da Silva. São Paulo: Martins Fontes, 2005.

DUBAR, C. Formação, trabalho e identidades profissionais. In: CANÁRIO, R. (Org.). Formação e situações de trabalho. Porto: Porto Editora, 1997.

FARIA FILHO, L. M.de (org.) Arquivos, fontes e novas tecnologias. Questões para a história da educação. Campinas: Autores Associados; Bragança Paulista, Universidade de São Francisco, 2000.

FERREIRA JR., A.; BITTAR, M. Proletarização e sindicalismo de professores na ditadura militar (1964-1985). São Paulo: Edições Pulsar \& Terras do Sonhar, 2006. 112 p.

LAWN. M. Os professores e a fabricação de identidades. Currículo sem Fronteiras, Portugal, v. 1, n. 2, p. 117-130, jul./dez. 2001

LAWN. M. Os professores e a fabricação de identidades. In: NÓVOA, A.; SCHRIEWER, J. (Org.) A difusão mundial da escola. Lisboa: Educa, 2000. p. 69-84.

LELIS, I. Profissão docente: uma rede histórias. Revista Brasileira de Educação, n. 17, p. 40-49, maio/ago. 2001.

NÓVOA, A. (Org.). Vidas de professores. 2. ed. Porto: LDA, 1995.

NÓVOA, A. Formação de professores e a profissão docente. In: NÓVOA, A. (Org.). Os Professores e a sua Formação. 2. ed. Lisboa: Dom Quixote, 1992. p. 15-33.

NÓVOA, A. Profissão professor: identidade e profissionalização docente. Brasília: Plano, 2002.

OLIVEIRA, D. A reestruturação do trabalho docente: precarização e flexibilização. Educ. Soc., v. 25, n. 89, dez. 2004

OLIVEIRA, D. As reformas educacionais e suas repercussões sobre o trabalho docente. In: OLIVEIRA, D. (Org.) Reformas educacionais na América Latina e os trabalhadores docentes. Belo Horizonte: Autêntica, 2003.

OLIVEIRA, D. Os trabalhadores docentes no contexto de nova regulação das políticas educacionais na América Latina. Belo Horizonte: Faculdade de Educação / UFMG, 2006. (Relatório de Pesquisa Capes).

PENIN, S. T. S. A satisfação/insatisfação do professor no trabalho. 1980. Dissertação (Mestrado) - Pontifícia Universidade Católica de São Paulo, São Paulo, 1980.

SAVIANI, D. Formação de professores: aspectos históricos e teóricos do problema no contexto brasileiro. Revista Brasileira de Educação, v. 14, n. 40, jan./abr. 2009.

Universidade Federal do Piauí. Diário Oficial União, Brasília, DF, 20 de agosto de 1969.

RPGE- Revista on line de Política e Gestão Educacional, Araraquara, v. 24, n. 3, p. 1615-1631, set./dez. 2020. e-ISSN:1519-9029 DOI: https://doi.org/10.22633/rpge.v24i3.14359 
XAVIER, L. N. O Brasil como laboratório: educação e ciências sociais no projeto do centro brasileiro de pesquisas educacionais. Bragança Paulista: IFAN / CDAPH/ EDUSF,1999.

\section{Como referenciar este artigo}

GONDINHO, M. R. R.; OLIVEIRA, L. X. MARTINS, M. C. R. Histórias profissionais: políticas de formação e percursos formativos de professores. Revista on line de Política e Gestão Educacional, Araraquara, v. 24, n. 3, p. 1615-1631, set./dez. 2020. e-ISSN:15199029. DOI: https://doi.org/10.22633/rpge.v24i3.14359

Submetido em: $30 / 06 / 2020$

Revisões requeridas: $20 / 07 / 2020$

Aprovado em:26/08/2020

Publicado em: 01/09/2020 